\title{
SMART DRIVING SYSTEM WITH AUTOMATIC DRIVER ALERT AND BRAKING MECHANISM
}

P. B. Dhanusha

Department of Electronics and communication Engineering, SAINTGITS College of Engineering Kottayam, Kerala, (India). E-mail: dhanusha.pb@saintgits.org ORCID: https://orcid.org/0000-0001-7375-168X

\section{A. Lakshmi}

Department of Electronics and Communication Engineering Kalasalingam

Academy of Research and Education Tamil Nadu, (India). E-mail: lakshmi@klu.ac.in ORCID: http://orcid.org/0000-0002-6744-7048

\section{K. Saravanan}

Department of Electronics and Communication Engineering, SAINTGITS College of Engineering Kottayam, Kerala, (India). E-mail: saravanan.k@saintgits.org ORCID: https://orcid.org/0000-0002-6160-3601

\section{Gitación sugerida:}

Dhanusha, P. B., Lakshmi, A., y Saravanan, K. (2020). Smart driving system with automatic driver alert and braking mechanism. $3 C$ Tecnología. Glosas de innovación aplicadas a la pyme. Edición Especial, Marzo 2020, 287-299. http://doi.org/10.17993/3ctecno.2020.specialissue4.287-299

\section{Suggested citation:}

Dhanusha, P. B., Lakshmi, A., \& Saravanan, K. (2020). Smart driving system with automatic driver alert and braking mechanism. 3C Tecnología. Glosas de innovación aplicadas a la pyme. Edición Especial, Marzo 2020, 287-299. http://doi.org/10.17993/3ctecno.2020.specialissue4.287-299 


\section{ABSTRACT}

Driving is one of the most important job for almost all people. Person use their vehicle to travel from one place to other. The count of automobiles is increasing every day. It increases the risk to accident. Currently, percentage numbers of accident are increasing drastically. One of the main reason for accident is the failure in concentration of the driver due to which he/she may fall asleep or sometimes due to the delay for applying the brake. A new system is developed that can solve these problems where an alert is given to the people present inside the vehicle to indicate that the driver is falling asleep and a co- system which can automatically stop the vehicle even if the driver may not brake manually due to obstacles. Our aim is to make a smart driving system with automatic waking alert and automatic braking system to ensure the safety of driving.

\section{KEYWORDS}

Smart, Automatic, Braking. 


\section{INTRODUCTION}

"Driving to save lives, time, and money in spite of the conditions around you and the actions of others" - one of the quotes for protective Driving.

Accidents are happening due to improper driving. The main causes for accidents are the drowsiness of the driver or unaware of surroundings. Driver drowsiness is found as a very important fact in the automobile accidents. It was observed that $20 \%$ of vehicle accidents occurs due to the increased drowsiness. We know that life that lost can't be re-winded. Accidents due to this reason can be avoided with the help of advanced electronic technology to an extent (Fisher \& Talwar, 2013).

Studies shows that drowsiness is one of the important reason for accidents and it can impair the brain of a human being as much as an alcohol can. In a survey it was found that, twenty three percentage of people have fallen asleep during driving. According to Department of Transportation, United States, the tendency for fallen asleep during driving for male is twice as much as female drivers. As claimed by the National Highway Traffic Safety Administration, drowsiness is the only factor in more than 100,000 accidents, causing 1,550 deaths and 40,000 bruise annually in USA.

The chances of accidents can be reduced by the effective use of advanced electronics technology. If all the vehicles are implanted with an automated security system such that the system provides good security to driver along with an alarm, we can decrease the chances of accidents. The percentage of accidents is increasing every day since the amount of vehicles is also increasing. The main reason for the accident is due to the delay caused by the driver to hit the brake. In order to stop this type of accidents, a system with automatic braking can be implemented. (Niehaus \& Stengel, 1991) The proposed system gives an automatic driver alert and braking mechanism by which the rate of accidents can be reduced. The important part of the system is a brain wave sensor. The sensor detects the drowsiness of the human being by sensing the brain waves. These waves are processed, and an alarm is operated if needed. The system also provides an additional facility of automatic braking if there is a delay in applying the brake by the driver. This system measures brainwave strength using brainwave sensor and give waking alert if the driver falls asleep. The system also gives automatic braking assistance using ultrasonic sensor. 


\section{MATERIALS AND METHODS}

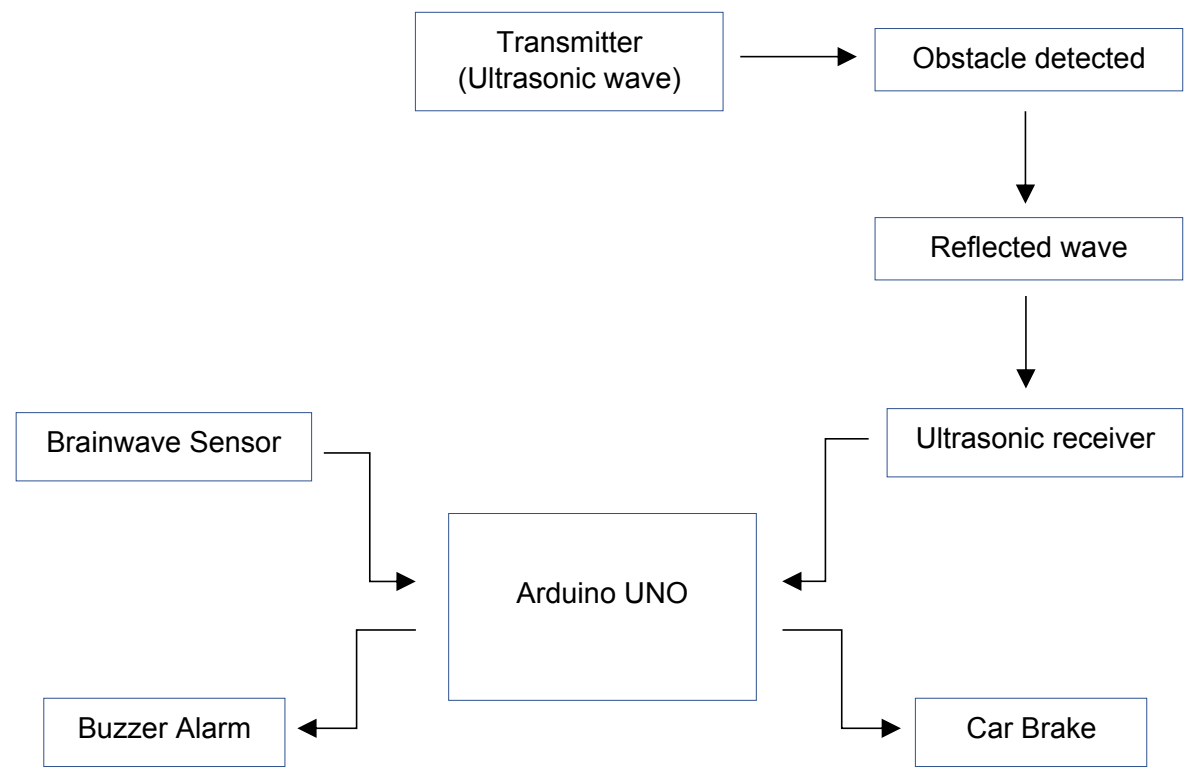

Figure 1. Overall block diagram.

The brainwaves are measured using the brainwave sensor and is analysed by the Arduino program. When the certain waves (mainly gamma) falls under a threshold value we can say the driver is going to fall asleep. When the threshold level is reached, we will give a buzzer alarm to wake the driver. The smart system consists of a sender and receiver which sends the ultrasonic waves and also receives. (Wang, Zeng, \& Yang, 2006) The ultrasonic signal emitter is fixed at the front of the automobile, which emits ultrasonic waves in a preset distance at the front of the automobile. Ultrasonic signal collector is also fixed in front of the car, which receives the ultrasonic wave which is reflected from the obstacle. The distance between the car and the barrier is measured by analyzing the received ultrasonic signal. Using the program which is programmed for automatic braking will control the braking system according to this distance. Brake is applied automatically to avoid forward collision.

\section{HARDWARE REQUIRMENT}

Arduino UNO, Mind-flex Brainwave sensor, Ultrasonic sensor, LEDs, Battery Operated motors, Buzzer, Bread board, Dot board, connecting wire 


\section{SOFTWARE REQUIREMENT}

Arduino programming $(\mathrm{c}++)$, Fritzing.

\section{WORKING OF CIRCUIT}

The important part of the smart system is a sender and receiver which sends the ultrasonic waves and also receives. The ultrasonic signal emitter is fixed at the front of the vehicle, which emits ultrasonic waves in a preset distance at the front of the vehicle. Ultrasonic signal collector is also fixed at the front of the car, which receives the ultrasonic signal reflected from the obstacle. The car and the barrier separation are measured by analyzing the obtained ultrasonic signal. The reflected wave is measured so that the separation between the automobile and the obstacle is obtained. This distance is analysed using the Arduino program and based on this signals are given to motor shield. According to these signals motor is controlled. Here we take $30 \mathrm{~cm}$ as alerting point, in which led will turned on and we take $20 \mathrm{~cm}$ as braking point in which automatically brake is applied. The brainwaves are measured using the Mindflex brainwave sensor and is analysed by the Arduino program. When the certain waves (mainly gamma) falls under a threshold value we can say the driver is going to fall asleep. When the threshold level is reached, we will give a buzzer alarm to wake the driver.

\section{SMART DRIVING}

The main idea is to merge the above two ideas and produce a smart driving system for driving especially at night. Because the chances of falling asleep and chances of collision with obstacles are very high compared to day. The block diagram indicating the same.

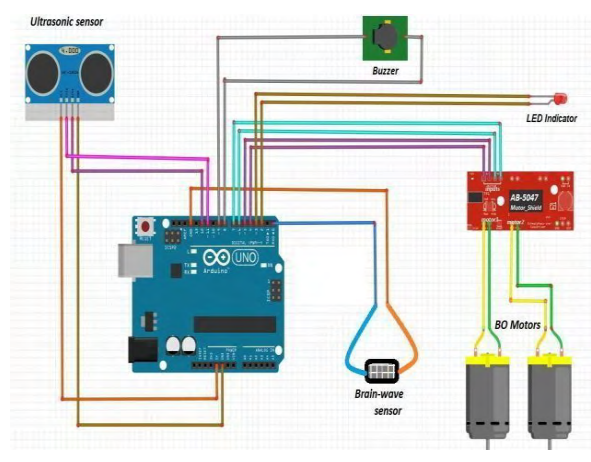

Figure 2. Circuit diagram. 


\section{COMPONENT DESGRIPTION}

\section{$\underline{\text { ARDUINO UNO }}$}

The sensing of the obstacle is done using Arduino. It is an open source companies that develops microcontroller kits which can senses/detect objects in the real world for different applications.

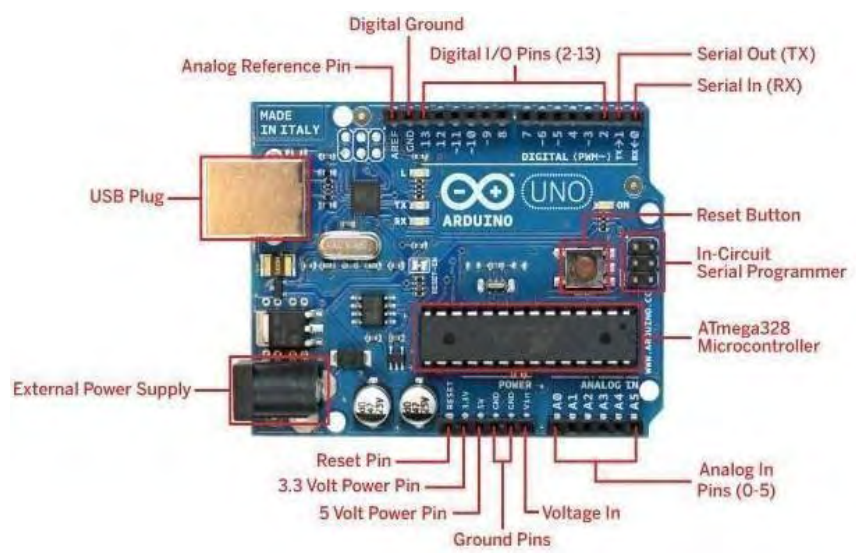

Figure 3. ARDUINO UNO.

It is possible to design Arduino boards by using different types of processors and controllers based on the application. It has many digital input and digital output pins by which the kit must be interfaced to other boards and electronic circuits. Some kits provide Universal Serial Bus (USB) connectors through which we can load programs from the personal computers. The integrated chip is generally programmed using $\mathrm{C}$ or $\mathrm{C}++$.

This work makes use of the Arduino board to interface all the components and they are run by a program compiled by Arduino software. The microcontroller used in Arduino Uno is ATmega 328P. Arduino Uno is the commonly used kit of the Arduino family. Arduino Uno has fourteen digital I/O pins, six analog input pins, a $16 \mathrm{MHz}$ quartz crystal, a power jack and a USB connection.

\section{ULTRASONIC SENSOR - HC-SR04}

The ultrasonic sensor used in the proposed system is HC-SR04. This sensor gives up to $400 \mathrm{~cm}$ of measurement with $3 \mathrm{~mm}$ ranging accuracy. The different modules included are an ultrasonic receiver, transmitter and a control circuitry. 


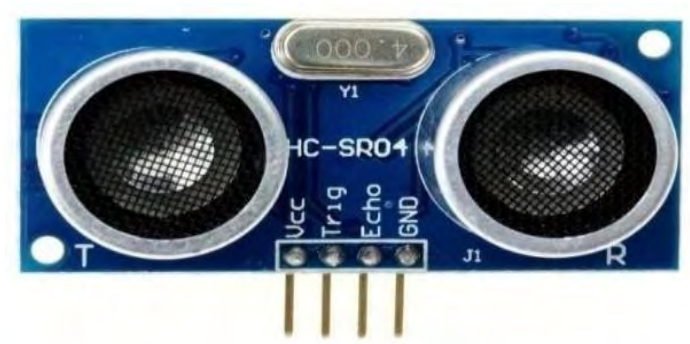

Figure 4. Ultrasonic sensor HC-SR04.

By analyzing the time delay between transmitted and received signal ofthe sensor, the range can be calculated.
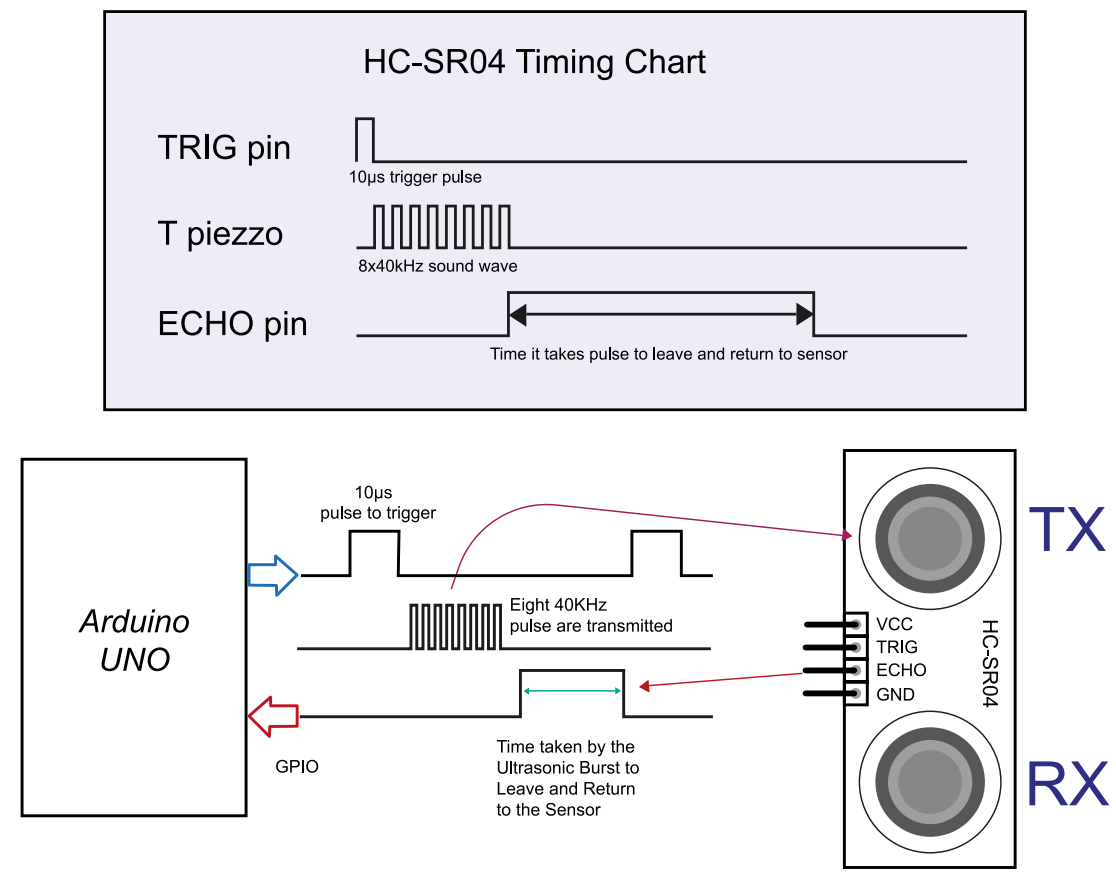

Figure 5. System Overview.

\section{BRAINWAVE SENSOR}

A sensor which can detect Brainwaves is known as a brainwave sensor. It will transform these brainwaves into electrical signals which can be used for the analysis. The figure shows a 'Mindflex' brainwave sensor which can detect brainwaves. This sensor can detect delta, theta, alpha, beta and Gamma waves of the brain. An electrode in the sensor have direct contact with the forehead of the person using the sensor which can detect brainwaves. 


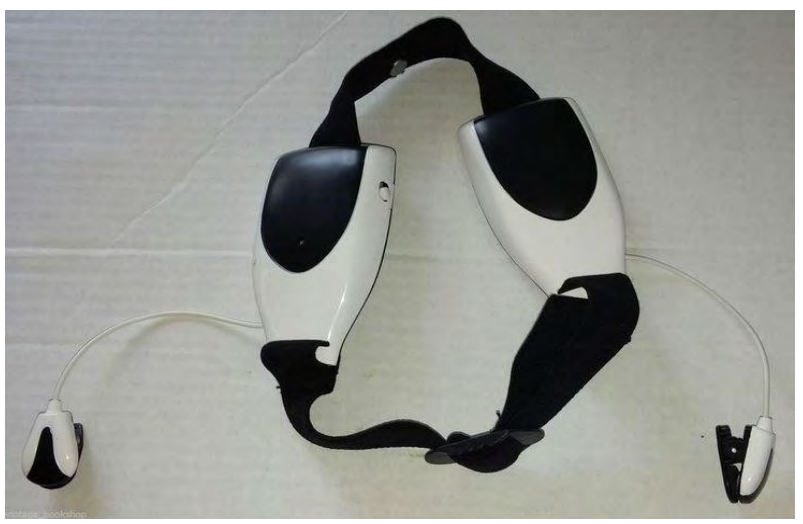

Figure 6. Brainwave sensor.

\section{BUZZER}

The signaling device used in this project is a buzzer. A signaling device has many applications like in automobiles, household appliances etc. A buzzer includes switches or sensors, which are controlled by a control unit that checks if and which button was pushed or a present time has lapsed, and blinks light on the appropriate button or control panel and sounds a warning in the form of beeping sound.

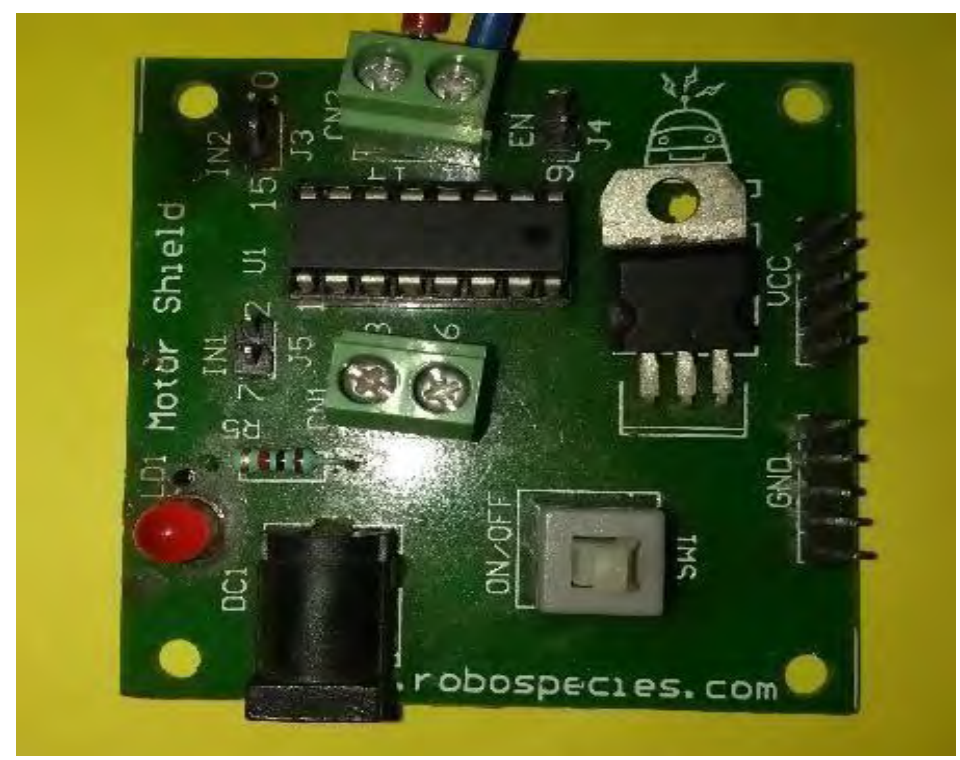

Figure 7. Arduino Motor Shield. 


\section{$\underline{\text { MOTOR SHEILD }}$}

For controlling the DC motors we are using an Arduino Motor Shield which is developed to control relays, DC motors, solenoids, and stepping motors. By using the Arduino board control of two DC motor is possible. Here WE are using AB 5407 Motor shield for Arduino.

\section{BRAINWAVES}

Brain wave sensor is placed on the scalp, which senses the brain waves. According to the condition of our mind the frequencies of the brain waves will be varied. A low frequency signal indicates tiredness. For hyper alert condition the brain waves will have high frequency. Brain waves are divided into different types based on the frequency (Mostafa, Mustapha, Hazeem, Khaleefah, \& Mohammed, 2018).

Different types of brainwaves:

\section{INFRA-LOW WAVES}

Infra-Low brainwaves are thought to be the basic cortical rhythms that underlie our higher brain functions. Very little is known about infra-low brainwaves. They come under frequency less than $0.5 \mathrm{~Hz}$. They appear to take a major role in brain timing and network function.

\section{DELTA WAVES}

Frequency of the delta waves ranges from $0.5 \mathrm{~Hz}-3 \mathrm{~Hz}$. They are slow brainwaves with low frequency and highly penetrating in nature. Delta waves are produced during meditation or dreamless sleep.

\section{THETA WAVES}

Theta waves come under the frequency range 3 to $8 \mathrm{~Hz}$. Theta waves are generated during sleep. Theta waves generally gives information about learning and memory.

\section{$\underline{\text { ALPHA WAVES }}$}

The frequency of alpha waves ranges from 8 to $12 \mathrm{~Hz}$. Alpha brainwaves are generated during quietly flowing thoughts. Alpha is the resting state for the brain. Alpha brainwaves aim overall mental coordination, learning, calmness, mind/body integration and alertness. 


\section{BETA WAVES}

The frequency range of Beta waves is from 12 to $38 \mathrm{~Hz}$. Beta waves are generated when we are alert and attentive.

\section{GAMMA WAVES}

Brain waves which comes under the frequency range 38 to $42 \mathrm{~Hz}$ is called gamma waves. Gamma brainwaves are the fastest of brain waves. It is speculated that Gamma rhythms modulate perception and consciousness, and that a greater presence of Gamma relates to expanded consciousness and spiritual emergence.

\section{ARDUINO SOFTWARE DESGRIPTION}

In this work the platform used is an Arduino integrated development environment also known as IDE, in which the programming is written in Java. IDE provides different features like text cutting, searching, pasting, replacing text, automatic indenting, and syntax highlighting. The programs are compiled and uploaded to the Arduino kit using a very simple one click mechanism. The other important highlights of IDE include a message area, a text console, a toolbar with buttons etc.

The audio programs written for IDE are known as sketch. This sketches are saved as text files in the development computer with the extension as ino. The languages supported by Arduino IDE are $\mathrm{C}$ and $\mathrm{C}++$ using special rules of code structuring.

\section{CONCLUSION}

A practical system (Automatic waking alert) which could detect whether the driver is going to fall asleep or the concentration level of the driver is too low is produced, it also gives alarm when the above situations occurs. An automatic braking system which could automatically apply brake if the driver takes too much time to manually apply the brake is also produced as part of this work.

We believe this system will reduce the chances of road accidents and ensure safe driving. 


\section{REFERENCES}

Borraz, R., Navarro, P. J., Fernández, G., \& Alcover, P. M. (2018). Cloud Incubator Car: A Reliable Platform for Autonomous. Driving. Applied Sciences, 8(2), 303. https:/ / doi.org/10.3390/app8020303

Fisher \& Talwar. (2013). Car Accident Statistics 2013. https://www.fishertalwar.com/caraccident-statistics/

John, S., \& Pedro, J. O. (2013). A comparative study of two control schemes for anti-lock braking systems. In 9th Asian Control Conference (ASCC), 1-6. https://doi.org/10.1109/ ASCG.2013.6606061

Lexus. (2017). Lexus Outlines Advanced Active Safety Technologies for All-Nere LS. https:// newsroom.lexus.eu/lexus-outlines-advanced-active-safety-technologies-for-all-newls/ (accessed on 20 December 2018).

Mi, G., Lin, H., \& Zhang, Y. (2009). Iterative learning control of antilock braking of electric and hybrid vehicle. IEEE Transactions on Vehicular Technology, 54(2), 486 -494. https://doi.org/10.1109/TVT.2004.841552

Modi, S., Chesnakov, D., Zhang, W. C., Lin, Y., \& Yang, G. S. (2012). A driverautomation system for brake assistance in intelligent vehicles. IEEE 10th International Conference on Industrial Informatics, 446-451. https://doi.org/10.1109/ INDIN.2012.6301063

Mostafa, S. A., Mustapha, A., Hazeem, A. A., Khaleefah, S. H., \& Mohammed, M. A. (2018). An Agent-Based Inference Engine for Efficient and Reliable Automated Car Failure Diagnosis Assistance. IEEE Access, 6, 8322-8331. https:// doi.org/10.1109/ACGESS.2018.2803051

Niehaus, A., \& Stengel, R. F. (1991). An expert system for automated highway driving. IEEE Control Systems Magazine, 11, 53-61. https://doi.org/10.1109/37.75579 
Wang, F.-Y., Zeng, D., \& Yang, L. (2006). Smart cars on smart roads: an IEEE intelligent transportation systems society update. IEEE Pervasive Computing, 5(4), 68-69. https:// doi.org/10.1109/MPRV.2006.84 
